\title{
Cultural Embedding: the Logic and Strategy of the Construction of Rural Civilization in the New Era
}

\author{
Zhanguang Hu \\ Huzhou Institute of Administration, 6SanTianMen Road, Huzhou City, Zhejiang Province, China
}

\begin{abstract}
Culture is the core element of local civilization, and its "embedded" characteristics and value are an important resources for the construction of local civilization. In the new era, the social environment in rural areas has undergone structural changes, and it is difficult to solve the public, organization and participation of the construction of rural customs and civilization to resolve themselves, and the root cause lies in the lack or absence of culture. Under the background of rural revitalization, through the integration of multiple cultural embedding into the rural social structure system, it plays an irreplaceable role in standardizing the rural order and building a rural community, and can inject new elements and new momentum into the construction of rural civilization. Based on this, taking "embeddings" as the theoretical framework and analysis tool, analyzed the internal logic of cultural embedding, and combined with the practice of rural civilization construction, discussed the feasibility of cultural embedding as rural civilization construction in Zhejiang Huzhou.
\end{abstract}

Keywords: Cultural embedding, Local customs and civilization, Rural governance.

\section{Introduction}

Rural civilization is an important part of rural public affairs governance. Since the Fifth Plenary Session of the 16th CPC Central Committee incorporated the construction of rural civilization into the main content of rural construction, the practical innovation and theoretical research on the construction of rural civilization has been gradually carried out. The 19th National Congress of the Communist Party of China put forward the rural revitalization strategy and took local civilization as one of the overall requirements. Later, the Opinions of the CPC Central Committee and the State Council on the Implementation of the Rural Revitalization Strategy, the Rural Revitalization Strategic Plan (2018-2022), the Guiding Opinions on Strengthening and Improving Rural Governance, and the Regulations of the Rural Work of China and other documents put forward specific and clear requirements on the principles, content and tasks of the construction of rural civilization. Over the past ten years, all walks of life have made remarkable achievements in the practical exploration and theoretical research of rural civilization, but the rural social environment in the new era, and the practical difficulties such as public, organization and participation of rural civilization construction are difficult to resolve themselves, and the fundamental reason is the loss and decline of rural culture.

Rural culture is the core element of local custom civilization, as Samuel Huntington said, "a civilization is one of the most extensive cultural entity, is magnified the culture, each rural, regional, ethnic groups, ethnic, religious groups at different levels of cultural heterogeneity has a unique culture, also created a variety of civilization"[1]. Rural culture is rooted in the rural social network, with the broadest ideological and behavior restraint functions, and plays an irreplaceable role in maintaining the rural community spiritual life and rural social order. On the contrary, if the rural culture is missing, the local civilization will lose its core support. "In the process of modernization, the loss of rural culture and the deviation of the cognition of rural cultural value are the main reasons for the collapse of rural civilization.”[2]

\section{Construction Logic: the Internal Interaction between Culture and Local Civilization}

Cultural field is the foundation of the construction of local civilization. "Any kind of civilization needs to take culture as the carrier to touch the essence of the civilization"[3]. Of course, local civilization is no exception. Through the embedding and integration of multiple cultural carriers, it can realize its value connotation and practical goals. The basic logic is that the cultural disconnection of rural social structure, which leads to the problem of individuality and atomization. Moreover, it will need culture to be embedded in rural value system and rural order, inject new impetus into the construction of rural civilization, and realize the dynamic balance of cultural embedding integration.

\subsection{Logical Starting Point: the Culture in the Construction of Rural Civilization Embedded}

Rural culture has its specific field and subject inheritance, can play in the "cohesion, civilization construction, integration, assimilation, standardize social group behavior and psychological function"[4], but when by the local custom "structural elements, variation and sudden drive, rural social structure, cultural integration, political and social forces intervention of gravity"[5], make rural culture in The evolution of times and modernization context, presents the rural social structure "embedded" phenomenon. Specific performance is: First, the loss of rural elite. Some rural elites are lost, rural hollowing out, aging, the lack of inheritance of traditional local culture and intangible cultural heritage of cultural elites, leading to the lack of drive in the construction of rural civilization. Second, the folk culture type of the micro. The excellent folk culture based on farmers' feelings and aesthetic expression of farmers in agricultural society has the educational role of guiding spiritual outlook and regulating subject behavior. However, under the change of The Times, 
influenced by the "external attraction" such as urbanization and urban culture, farmers' production and life style has changed, and folk feelings have also been weakened. Third, the fragmentation of rural moral rules. The transformation of production mode and role differentiation deconstructs the traditional rural social structure, profoundly affects the value orientation and personal mentality of farmers, and makes the traditional moral bearing basis fragmented and marginalized. Fourth, the lack of effective carriers.

\subsection{Middle Process: the Cultural Embedding in the Construction of Rural Civilization}

Throughout history, contemporary Chinese rural culture is not invariable, it is constantly embedded in the state of fusion, especially after the revolutionary culture of the communist party of China and socialist culture embedded in the countryside, constitute the rural cultural change of "multi-layer nested structure"[6], so can say "embedded is the fundamental characteristics of the development of contemporary Chinese rural culture" has entered a new era, and there is a certain culture in the construction of rural civilization. It needs the culture to be embedded in the rural social structure and spiritual life again to make up for the internal spiritual deficiency in the countryside. One is embedded in the value system. Since farmers get rid of the collective "organizational attachment", rural society gradually tends to "individualized", "rural traditional value fission", collective "standard" to "family, individual standard", leading to "in such an individualized society, farmers, especially the younger generation of farmers have not exist any 'public' or 'collective' consciousness", which is also the historical reason for the construction of rural civilization difficulties in the new era. Second, it is embedded in the rural order. Zhao Xia believes that the standard value of rural culture lies in the formation of rural "life order", "spiritual order" and "spontaneous order"[7]. However, in reality, the lack of discourse power in rural culture shocks the foundation of cultural identity and eliminates the "three orders". It is urgent for culture to be embedded and reshape the cultural discourse power.

\subsection{Value Goal: Cultural Integration in the Construction of Rural Civilization}

The construction of local civilization drives cultural "unembedding" and multiple "embedding" links through internal and external forces, which will form a dynamic cultural integration system of traditional and modern, history and reality, which is the value orientation and main goal of the construction of local culture in the new era. Its basic performance is, on the one hand, is the embedded integration of the internal elements of the rural social and cultural system. As a natural existence system or "natural community"[8], its internal continuity and stability cannot be separated from the coordination and balance between internal informal systems. "The morality, values and various cultures of local civilization do not exist in isolation, but are embedded and integrated"[9]. In particular, value and beliefs, cultural traditions, customs, ethics and ideology are embedded and integrated with each other, forming a stable social and cultural network system in rural areas. On the other hand, the integration of culture embedded between host and objects. Boudeeu believes that self-creativity is the most fundamental feature of culture, which can itself be rebuilt and updated through the "reproduction" mode. That is to say, "the rural culture in the change of local society will not be eliminated, nor will it be easily replaced by foreign culture. In the face of many social trends, it will constantly transform and produce new forms of expression under the help of internal adaptation mechanism." The new form of [10] is that the integration of the advanced culture as the embedded subject and the rural culture as a rural cultural object is finally realized in the new conditions.

\section{Practice and Exploration: Case Analysis of Local Customs and Civilization}

\subsection{Embedded Subject: the Integration of Excellent Traditional Culture}

The analysis of cultural embedding theory from the perspective of rural cultural change generally points to two related objects: embedded subject and embedded object. Embedded body representation leading, dominant and active culture, such as the revolutionary culture and advanced socialist culture since modern times is embedded subject, constantly embedded in rural society; embedded object mainly shows independence, passive, in the transformed or "embedded" state or active adsorption state. For the construction of rural civilization, the connection between the traditional culture and the countryside is the most natural and close, and it is the most effective and lasting embedded subject. Excellent traditional culture is embedded in the countryside, and the key is to embed the ideas and moral norms into the people's daily life, and change the status quo of the "disconnection" of traditional rural culture in the past. Therefore, the construction of local civilization must adhere to the needs of the masses as the oriented. From practice, Huzhou countryside contains rich etiquette culture, farming culture and folk culture, which is mainly realized by integrating into the life of grass-roots people. Active Embedded. The expression form of traditional culture is mainly popular and popular activities, embedded in its excellent ideas in the form of activities. Active Embedded. The embedded body is in the active position, focusing on meeting the cultural needs of the masses, improving the spiritual outlook, and changing the state of cultural "out of embedded". Hematopoietic embedding. To create civilized local customs, cultural embedding is the driving force, and embedding and integration into economic and social development is the purpose. While taking the "blood transfusion" of rural culture, more attention should be paid to cultural "hematopoiesis", so as to transform cultural resources into economic resources. 


\subsection{Embedded Field: the Duality of Beautiful Countryside Construction}

Rural is the field of cultural embedding, but in real practice, there needs to have specific fields as the entry and support. For Huzhou and even Zhejiang, the construction of beautiful countryside is an important field and foundation for promoting rural civilization and implementing the rural revitalization strategy. From the perspective of development, the construction of beautiful countryside is different from the previous construction of new countryside. It not only makes achievements at the material level, but also pays more attention to the achievements at the level of civilization, and highlights the attributes of rural civilization and rural rejuvenation. It can be seen that the construction of beautiful countryside has two aspects, on the one hand, pay attention to the improvement of hardware, focus to promote the improvement of rural living environment, reflect the "beautiful and livable" countryside; on the other hand, pay attention to the improvement of software, focus on the revival of rural civilization, cultural connotation, reflect the "civilized and orderly" local customs. It is the two internal and external attributes of the construction of beautiful countryside that make two directions to the construction of beautiful countryside, one is "tangible embedding". By protecting the historical and cultural villages, traditional buildings, intangible cultural heritage and other traditional cultural material carriers, endowed and embedded cultural elements, make them renew a new life. The other is the "intrinsic embedding". The internal embedding is mainly embedded in the civilization level of the beautiful countryside, and the theme is the civilization and moral problems of the grass-roots people. Huzhou city with beautiful rural construction as the theme, with mass spiritual civilization creation activities as the carrier, in-depth the implementation of "farmers spirit, culture benefit agriculture, rural civilization create" three promotion action, vigorously carry out the "beautiful courtyard", "star civilization", "the most beautiful family" "civilized family" civilization creation activities, the beautiful rural construction and local custom civilization construction organic integration.

\subsection{Embedded Method: the Mediation of Grass-Roots Autonomous Organizations.}

In the past, the problems of public, organizational and participation in the construction of rural civilization were mainly affected by the logic of multiple subjects, and there are often hiking "phenomenon, resulting in the 'dilemma of collective action"'[11]. For example, the grass-roots government, based on rational choice, tends to "pay attention to the construction of local customs and civilized hardware, ignore the connotation development, ignore the wishes of the villagers, reject the participation of the masses, and selectively implement policies and other behaviors"[12]. The village two committees tend to seek profit and avoid harm, "the construction of rural civilization is difficult to be profitable, the villagers are not strong, and their own lack of necessary knowledge, village cadres often take a formal strategy." Some[13] villagers show individualized in the construction of rural civilization. Without increasing personal income, they will be constrained, there will be passive and exclusive behavior. It can be seen that the construction of local customs and civilization in the new era should be based on the behavior logic analysis of multiple subjects, and explore new ways of organization and participation. From the perspective of governance, the key to the difficulty of grass-roots people to participate in the construction of rural civilization lies in the lack of intermediate carrier between grass-roots government and grass-roots people, which makes it difficult for different subjects to effectively communicate and negotiate, and achieve the consistency of behavior. Based on this, various localities have set up various grass-roots autonomous organizations in the construction of local customs and civilization, and absorb and integrate all kinds of subjects to participate in rural affairs. From Huzhou practice, in recent years, Huzhou around changing customs, advocating civilization, establish local sage council, and council, red and white, moral council, local council, moral clinic, autonomous organizations, through education, rules, organization construction, absorb retired party members and cadres, village sages, ordinary masses, entrepreneurs, give play to the main function of moral supervision and local custom evaluation, leading civilized local custom by public opinion. For example, in Zhangjiadai Village, Wuxing District, the "idle affairs" in the village are often inaccessible to laws and regulations and are submitted to the villagers' moral evaluation committee. It not only regularly evaluates good people and good deeds, selects good villagers, mother-in-law, mother-in-law and daughter-in-law, but also on the spot in case of neighborhood disputes and uncivilized phenomena.

\subsection{Embedded Mechanism: the Standardization of Governance Technology and Operation}

The standardization of the construction of rural civilization provides institutional guarantee for the cultural embedding and integration of the construction of rural civilization. At present, with culture embedded in rural social structure has become a consensus, Chinese excellent traditional culture, the communist party of China revolutionary culture everywhere received unprecedented attention and protection, some culture-related informal system such as rules, customs, habits, tradition also have revival trend, this is a favorable opportunity for rural civilization construction, but local custom civilization construction not only has its traditional side, also faces the problem of modernization, more need modern formal system norms and guarantee. In December 2018, Huzhou released the first local standard - the Code for the Construction of Rural Spiritual Civilization (hereinafter referred to as the Code) to China in the field of rural spiritual civilization construction, which provided experience and standard reference for the construction of rural spiritual civilization in Zhejiang Province and even the whole country. This is the construction constructing three mechanisms. First, the linkage mechanism. The Code clarifies the overall requirements of "ecological guidance, regional creation, local civilization, cultural prosperity and harmonious development" in the construction of rural spiritual civilization. This shows that under the rural revitalization strategy, 
beautiful countryside, rural civilization, cultural revitalization and rural governance should be promoted together, embedded, penetrate and promote each other to form overall benefits. Second, the accommodation mechanism. The main content of the Code involves four parts: local customs, cultural life, living environment and civilization creation, among which the local customs highlights the themes of thought, morality, villager culture, family rules and family instruction, which tend to be civilized, more inclusive, and easy to absorb to embed, interact and integrate different cultural elements. Third, the integration mechanism. "Code" has a strong institutional nature, which can modify and adjust the elements of different content, form, function and value orientation, to form a new operating system, which itself has an integration function. For the construction of local customs and civilization, different cultural elements, governance elements and hardware elements are embedded and integrated with each other, constantly update and develop, and maintain the vitality of civilized local customs.

Standardization is the practical demand of the modernization of governance. The construction of local customs and civilization needs "soft law", but also institutionalized and standardized regulations to ensure the orderly operation of its specific operation. From the perspective of norms, compared with laws and regulations, standards have specific quantitative requirements, but also more "human touch", its wider play space, can directly penetrate into the daily life of the masses, which can be embedded in the construction of rural civilization, and provide more direct, flexible and targeted embedded channels and embedding space. At the same time, as the standard is the technical tool of the construction of rural civilization, connects, accommo, integrates economic, political, cultural, social and other aspects, further optimize the allocation of resources, and enhance the degree of integration of culture and the construction of rural civilization.

\section{Epilogue}

In general, the construction of rural civilization in the new era, based on the interactive logic of culture and rural civilization, shows inclusiveness and entry. On the one hand, emphasize the inclusiveness of local custom civilization construction, especially to multiple embedded interaction and open, build embedded field and space, including the advanced socialist culture, red culture, traditional culture, etc., even urban culture, western culture, it contains reasonable contract spirit, competitive spirit, can be embedded subject, through local custom civilization construction platform or organization, increase the opportunity of different culture embedded integration, get rid of the rural culture "embedded" state. However, it is worth noting that cultural multiple embeddings, not external cultural embedding replaces the existing local culture, leading to the embedded object to encounter external impact and produce negative effects. On the other hand, need to explore the effective entry point of cultural embedding, not simply mechanically nested, but according to the rural social and cultural development law, absorb integrated external power and rural governance autonomy, unicom traditional and modern, urban and rural, local and foreign barriers, in embedded field, embedded, embedded mechanism to explore embedded organic embedded coupling space and opportunity. In addition, in the state of multiple cultural embedding, beware of the rural cultural inheritance or lack of innovation subjects, leading to problems such as low efficiency of embedding integration and breakthrough through the embedding boundary. To this end, starting with the rural social structure system, cultivate rural cultural subjects through multiple channels, and improve the consciousness of culture embedded in the execution subject.

\section{References}

[1] Samuel, Huntington. Conflict of civilization and the reconstruction of the world order $[\mathrm{M}]$. Zhou Qi et al. Beijing: Xinhua Publishing House, 2010: 20-21.

[2] $\mathrm{Xu}$ Yue. Construction of rural civilization under the background of rural revitalization strategy $[\mathrm{J}]$, Red Flag Document 2019 (21).

[3] Arnold Tang ynby, Cao Weifeng. Historical Studies (upper, middle, and bottom) [M]. Shanghai: Shanghai People's Press House, 1986.

[4] Dong Huan. Local civilization: the soul of building a new socialist countryside [J]. Lanzhou Journal, 2007(03): 75-78.

[5] Zhu Xiongjun. Ideal type analysis of the changing dynamics-based on the perspective of "structure-action" [J]. Sociological Review, 2013, 1(03): 86-96.

[6] Wang Sibin. The Embedded Development of Social Work in China [J]. The Social Science Front, 2011 (02):206-222

[7] Zhao Xia. Order crisis and value reconstruction of traditional rural culture $[\mathrm{J}]$. Rural China Observation, 2011 (03): 80-86.

[8] Ferdinand Tennis. Community and Society: The Basic Concept of Pure Sociology [M]. Beijing: The Commercial Press, 1999.

[9] Tang Xingjun, Li Dingguo. Cultural embedding: the value orientation and realistic path of rural style and civilization construction in the new era $[\mathrm{J}]$. Reality, 2019(02): 86-96+112.

[10] Zhao Xudong, Sun Xiaofei. Reproduction of Chinese rural culture-based on a concept of cultural transformation [J]. Journal of Nanjing Agricultural University (Social Sciences Edition), 2017, 17(01) $119-127+148$

[11] Olson. Logic of collective action [M]. Chen Yu et al., translation. Shanghai: Shanghai People's Press House, 1995:1.

[12] Guo Junmin. On the governance mechanism innovation of the township Government in the construction of rural civilization [J]. Journal of Xinxiang College (Social Sciences Edition), 2012 (2): 9-11.

[13] ]Huang Xin, Wu Hengtong, Zhang Zhenguo.Multiple logic of rural civilization construction-is based on the investigation and analysis of 14 cities and states in Hunan Province [J].Journal of Jishou University (Social Sciences Edition), 2019,40 (04): 124-133. 